\title{
Evaluating the Efficacy of Radiological Investigations of Adenomyosis with Clinical Symptomatology
}

\author{
Amanat Sidhu ${ }^{1}$, Sangeeta Pahwa ${ }^{2}$
}

\begin{abstract}
Introduction: Adenomyosis is a benign gynecological condition that predominantly affects women in the late reproductive age. It is a real challenge in healthcare with prevalence ranging from 5 to $70 \%$. It is characterized by uterine enlargement caused by ectopic rests of the endometrium within the myometrium. It is mainly associated with abnormal menstrual bleeding and severe dysmenorrhea. But now it can be done by advanced imaging modalities like transvaginal ultrasound (USG) and magnetic resonance imaging (MRI).

Materials and methods: A prospective longitudinal study was conducted from November 1,2018 to January 31,2020 on subjects with complaints of abnormal uterine bleeding and or with dysmenorrhea in the department of obstetrics and gynecology (OBG) of a tertiary care hospital and medical institution. Various medical and surgical treatments were offered on merit depending on age group and clinical symptomatology. The subjects were followed up for a minimum period of six months thereafter.

Results: It was found that out of the patients who had visual analog scale (VAS) score less than 7, 22.58\% had adenomyosis with normal uterus while $12.90 \%$ had bulky uterus with adenomyosis on ultrasound. Of the patients who had VAS score more than or equal to $7,9.68 \%$ had adenomyosis with normal uterus while $54.84 \%$ had bulky uterus with adenomyosis. MRI supplemented the ultrasound findings and was found useful in the confirmation of adenomyosis.

Conclusion: The clinical diagnosis of adenomyosis has been called enigmatic largely because there are no pathognomonic symptoms of this disease. Ultrasound and MRI are found to be highly useful in supplementing the correct diagnosis of adenomyosis.

Keywords: Adenomyosis, Dysmenorrhea, Magnetic Resonance Imaging, Ultrasound.

AMEl's Current Trends in Diagnosis \& Treatment (2020): 10.5005/jp-journals-10055-0103
\end{abstract}

\section{INTRODUCTION}

Adenomyosis is a condition in which there is uterine enlargement caused by ectopic rests of the endometrium - both glands and stroma-located within the myometrium.

Adenomyosis is a benign disease that predominantly affects women in the late reproductive age. The prevalence ranges from 5 to $70 \%$. In a study done by Naftalin et al., in London, the incidence of adenomyosis in the infertile population was found out to be $20.9 \% .^{2}$ Amongst abnormal uterine bleeding (AUB) in the perimenopausal age group, $44.56 \%$ had a finding of adenomyosis on histopathology. ${ }^{3}$ Pelvic endometriosis co-exists in about $40 \%$ of cases.

The structural causes of AUB include-P, polyp; A, adenomyosis; $\mathrm{L}$, leiomyoma; $\mathrm{M}$, malignancy; and hyperplasia. The non-structural causes include-C, coagulopathy; $\mathrm{O}$, ovulatory dysfunction; $\mathrm{E}$, endometrial; I, iatrogenic; and N, not yet specified. ${ }^{4}$

Adenomyosis is an important cause of AUB, mainly associated with dysmenorrhea. Clinical presentations include AUB, heavy menstrual bleeding, intermenstrual bleeding, dysmenorrhea, and infertility.

An abdominal examination shows a hypogastric mass arising out of the pelvis and occupying the midline with a size that does not usually exceed 14 weeks pregnant uterus. Pelvic examination shows a uniformly enlarged uterus.

Ultrasound is the primary modality for diagnosing adenomyosis. Ultrasound findings include heterogeneous myometrial echotexture, myometrial cysts. Asymmetry of anterior-posterior myometrium is seen along with a diffuse spread of vessels within the myometrium.
1Department of Obstetrics and Gynaecology, Sri Guru Ram Das
University of Health Sciences, Amritsar, Punjab, India
${ }^{2}$ Department of Obstetrics and Gynaecology, Sri Guru Ram Das
Institute of Medical Sciences and Research, Amritsar, Punjab, India
Corresponding Author: Sidhu A, Pahwa S, Department of
Obstetrics and Gynaecology, Sri Guru Ram Das University of Health
Sciences, Amritsar, Punjab, India, Phone: +91 9808777772, e-mail:
amanatchhina3@gmail.com
How to cite this article: Sidhu A, Pahwa S. Evaluating the Efficacy
of Radiological Investigations of Adenomyosis with Clinical
Symptomatology. AMEl's Curr Trends Diagn Treat 2020;4(2):65-68.
Source of support: Nil
Conflict of interest: None

A study done by Exacoustos et al. found that a 2D-trans-vaginal ultrasound (TVUS) volume measurement $\left(\mathrm{cm}^{3}\right)$, calculated by an ellipsoid formula was higher for women with adenomyosis than those with histologically confirmed adenomyosis. ${ }^{3}$

On a coronal view of 3D-TVUS, the junctional zone can be identified as a hypoechoic area around the endometrium and distortion or infiltration of the hypoechoic inner myometrium.

Levgur et al. used a grading system to describe the depth of adenomyotic foci, such as deep (>80\%), intermediate (40-80\%), and superficial $(<40 \%)^{5}$

$\mathrm{MRI}$ is more accurate for the diagnosis. Low signal junctional zone $(\mathrm{JZ})<8 \mathrm{~mm}$ excludes diagnosis whereas $\mathrm{JZ}>12 \mathrm{~mm}$ is suggestive of adenomyosis. 
Imaging techniques, including 2D or 3D ultrasound and MRI, allow localization of the different types of adenomyosis (diffuse and focal). Therefore, an integrated non-invasive diagnostic approach is proposed to diagnose adenomyosis. ${ }^{6}$

To correlate the type and degree of adenomyosis scored through a new system based on the features of transvaginal sonography, to patients' symptoms and fertility a multicenter, observational, prospective study was conducted in 2019 at the University of Rome "Tor Vergata" and University of Siena. Higher values of menstrual bleeding were found for severe diffuse adenomyosis, with the highest values being found in those with adenomyomas. ${ }^{7}$

A study done by Champaneria et al. concluded that both MRI and ultrasound had high levels of accuracy in diagnosing adenomyosis. TVUS having $72 \%$ sensitivity and $81 \%$ specificity vs MRI having $77 \%$ sensitivity and $89 \%$ specificity. ${ }^{8}$

The present study was planned to validate various diagnostic modalities at different ages targeting the symptomatology.

\section{Materials and Methods}

A longitudinal study was conducted on subjects visiting the outpatient department of OBG in tertiary care hospital and medical institution for 18 months beginning from November 1, 2018 to January 31, 2020.

Clearance from the Ethical Committee was taken before the start of the study.

The age of subjects range from 30 to 55 years with complaints of abnormal uterine bleeding with or without dysmenorrhea were recruited. In the case of menstrual abnormalities, a detailed record of menstrual rhythm was noted. The record of the previous three cycles was maintained.

Detailed history including personal and family history was taken. Any investigation and treatment already undertaken were recorded.

\section{Inclusion Criteria}

- Cases with heavy menstrual bleeding.

- Cases with dysmenorrhea.

- Cases of AUB associated with endometriosis.

\section{Exclusion Criteria}

- Malignancy of uterus, tubes, and ovary.

- Leiomyoma-clinical and diagnosed on imaging.

- Any cases of polyp.

- Coagulopathy as the cause of AUB.

- Ovarian causes of AUB.

- Endometrial hyperplasia.

- Copper-T menorrhagia.

Radiological investigations including TVS ultrasound with color Doppler was done. MRI was requisitioned for confirmation of diagnosis.

Heavy menstrual bleeding was assessed from history, examination, number of pads used, and pictorial blood assessment chart (PBAC) score.

Dysmenorrhea was assessed from history, observing pain, the need for analgesics, and VAS score.

Anemia was seen from pallor, other symptoms like lethargy and confirmed by lab testing (complete blood count).

$\mathrm{PV}$ (per-vaginal)/PR (per-rectal)/PS (per-speculum) examination was done in patients appropriate for age, marital status, and to know pelvic anatomy and pathology in view of PALM-COEIN classification for the inclusion of adenomyosis.

The patient was subjected to TVS-USG for knowing pelvic anatomy and pathology. MRI was done.

\section{Statistical Analysis}

The data from the present study was systematically collected, compiled, and statistically analyzed to draw relevant conclusions. Data were analyzed by using the $X^{2}$ test, T-test, and ANOVA. The $p$-value was determined finally to evaluate the levels of significance. The $p$-value of $>0.05$ was considered non-significant and the $p$-value of 0.01-0.05 was considered significant. The results were then analyzed and compared to previous studies. SPSS-22 version of the software was used, released 2013, Armonk, NY: IBM Corp.

\section{Results}

Patients were categorized according to age (Table 1).

Out of 31 patients, $90.32 \%$ presented with heavy menstrual bleeding, and $9.68 \%$ presented with pelvic pain. All patients had dysmenorrhea during menses as shown in Table 2.

A total of $32.26 \%$ of patients had adenomyosis with normal size uterus while $67.74 \%$ of patients had bulky uterus with adenomyosis. Maximum patients were in the age group 41-45 years out of which $12.9 \%$ of patients had adenomyosis with normal size uterus while $19.35 \%$ of patients had bulky uterus with adenomyosis as shown in Table 3.

In $32.26 \%$ of patients who had adenomyosis with normal size uterus on ultrasound, $25.81 \%$ had bleeding for less than 7 days while $6.45 \%$ had bleeding for more than or equal to 7 days. In $67.74 \%$ of patients who had bulky uterus with adenomyosis on ultrasound, $38.71 \%$ had bleeding for less than 7 days while $29.03 \%$ had bleeding for more than or equal to 7 days as shown in Table 4.

Out of the patients who had VAS score less than $7,22.58 \%$ had adenomyosis with normal uterus while $12.90 \%$ had bulky uterus with adenomyosis as shown in Figure 1. Of the patients who had VAS score more than or equal to $7,9.68 \%$ had adenomyosis with normal uterus while $54.84 \%$ had bulky uterus with adenomyosis as shown in Table 5.

Table 1: Age distribution

\begin{tabular}{lcc}
\hline Age group & No. of cases & Percentage \\
\hline $30-35$ & 8 & 25.81 \\
$36-40$ & 6 & 19.35 \\
$41-45$ & 10 & 32.26 \\
$46-50$ & 5 & 16.13 \\
$>50$ & 2 & 6.45 \\
Total & 31 & 100.00 \\
\hline
\end{tabular}

Table 2: History of present illness

\begin{tabular}{lcc}
\hline History of present illness & No. of cases & Percentage \\
\hline Heavy menstrual bleeding & 28 & 90.32 \\
Pelvic pain & 3 & 9.68 \\
Total & 31 & 100.00 \\
\hline
\end{tabular}


Evaluating the Efficacy of Radiological Investigations of Adenomyosis with Clinical Symptomatology

Table 3: Correlation of age distribution with ultrasound findings

\begin{tabular}{|c|c|c|c|c|c|c|}
\hline \multirow[b]{3}{*}{ Age group } & \multicolumn{4}{|c|}{ Ultrasound findings } & & \\
\hline & \multicolumn{2}{|c|}{$\begin{array}{l}\text { Adenomyosis with } \\
\text { normal size uterus }\end{array}$} & \multicolumn{2}{|c|}{$\begin{array}{l}\text { Bulky uterus with } \\
\text { adenomyosis }\end{array}$} & \multicolumn{2}{|c|}{ Total } \\
\hline & No. & $\%$ & No. & $\%$ & No. & $\%$ \\
\hline $30-35$ & 4 & 12.90 & 4 & 12.90 & 8 & 25.81 \\
\hline $36-40$ & 0 & 0.00 & 6 & 19.35 & 6 & 19.35 \\
\hline $41-45$ & 4 & 12.90 & 6 & 19.35 & 10 & 32.26 \\
\hline $46-50$ & 2 & 6.45 & 3 & 9.68 & 5 & 16.13 \\
\hline$>50$ & 0 & 0.00 & 2 & 6.45 & 2 & 6.45 \\
\hline Total & 10 & 32.26 & 21 & 67.74 & 31 & 100.00 \\
\hline
\end{tabular}

$X^{2}: 5.373 ; d f: 4 ; p=0.251$

Table 4: Correlation of the number of days of bleeding with ultrasound finding

\begin{tabular}{|c|c|c|c|c|c|c|}
\hline \multirow{3}{*}{$\begin{array}{l}\text { Bleeding } \\
\text { days }\end{array}$} & \multicolumn{4}{|c|}{ Ultrasound findings } & \multirow{2}{*}{\multicolumn{2}{|c|}{ Total }} \\
\hline & \multicolumn{2}{|c|}{$\begin{array}{l}\text { Adenomyosis with a } \\
\text { normal-sized uterus }\end{array}$} & \multicolumn{2}{|c|}{$\begin{array}{l}\text { Bulky uterus with } \\
\text { adenomyosis }\end{array}$} & & \\
\hline & No. & $\%$ & No. & $\%$ & No. & $\%$ \\
\hline$<7$ & 8 & 25.81 & 12 & 38.71 & 20 & 64.52 \\
\hline$\geq 7$ & 2 & 6.45 & 9 & 29.03 & 11 & 35.48 \\
\hline Total & 10 & 32.26 & 21 & 67.74 & 31 & 100.00 \\
\hline
\end{tabular}

$X^{2}: 1.546 ; d f: 1 ; p=0.214$

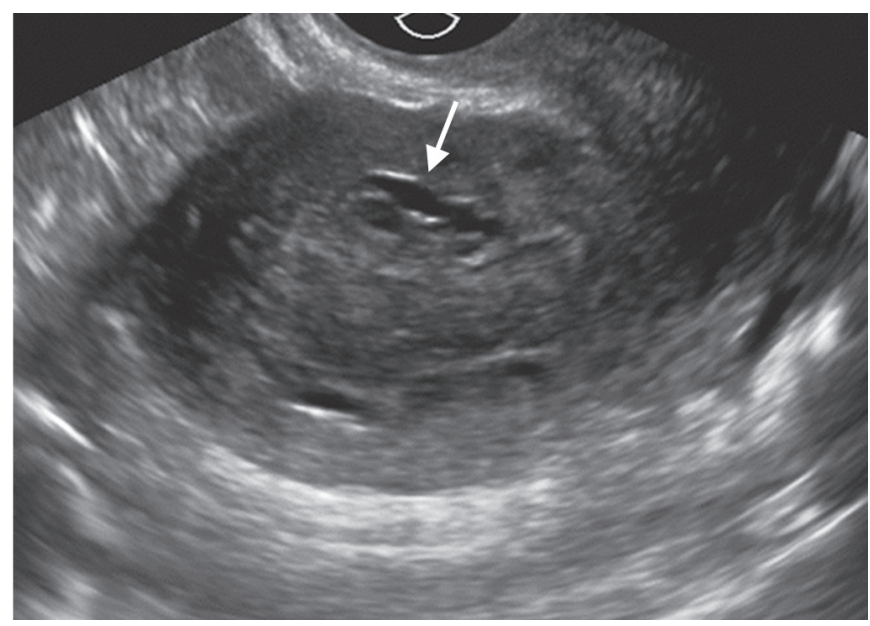

Fig. 1: Anechoic cysts and ectopic endometrium within the myometrium suggestive of adenomyosis

Table 5: Correlation of dysmenorrhea VAS score with ultrasound findings

\begin{tabular}{|c|c|c|c|c|c|c|}
\hline \multirow{3}{*}{$\begin{array}{l}\text { Dysmenorrhea } \\
\text { (VAS score) }\end{array}$} & \multicolumn{4}{|c|}{ Ultrasound findings } & \multirow{2}{*}{\multicolumn{2}{|c|}{ Total }} \\
\hline & \multicolumn{2}{|c|}{$\begin{array}{l}\text { Adenomyosis with } \\
\text { normal uterus }\end{array}$} & \multicolumn{2}{|c|}{$\begin{array}{l}\text { Bulky uterus with } \\
\text { adenomyosis }\end{array}$} & & \\
\hline & No. & $\%$ & No. & $\%$ & No. & $\%$ \\
\hline$<7$ & 7 & 22.58 & 4 & 12.90 & 11 & 35.48 \\
\hline$\geq 7$ & 3 & 9.68 & 17 & 54.84 & 20 & 64.52 \\
\hline Total & 10 & 32.26 & 21 & 67.74 & 31 & 100.00 \\
\hline
\end{tabular}

Table 6: Correlation of age distribution with MRI findings

\begin{tabular}{|c|c|c|c|c|c|c|}
\hline \multirow[b]{3}{*}{ Age group } & \multicolumn{4}{|c|}{$M R I$} & & \\
\hline & \multicolumn{2}{|c|}{$\begin{array}{l}\text { Adenomyosis with } \\
\text { normal uterus }\end{array}$} & \multicolumn{2}{|c|}{$\begin{array}{l}\text { Bulky uterus with } \\
\text { adenomyosis }\end{array}$} & \multicolumn{2}{|c|}{ Total } \\
\hline & No. & $\%$ & No. & $\%$ & No. & $\%$ \\
\hline 30-35 & 2 & 20.00 & 1 & 10.00 & 3 & 30.00 \\
\hline $36-40$ & 0 & 0.00 & 3 & 30.00 & 3 & 30.00 \\
\hline $41-45$ & 1 & 10.00 & 2 & 20.00 & 3 & 30.00 \\
\hline $46-50$ & 1 & 10.00 & 0 & 0.00 & 1 & 10.00 \\
\hline Total & 4 & 40.00 & 6 & 60.00 & 10 & 100.00 \\
\hline
\end{tabular}

$X^{2}: 4.447 ; \mathrm{d} f: 3 ; p=0.217$

A total of $40 \%$ of patients had adenomyosis with normal size uterus while $60 \%$ of patients had bulky uterus with adenomyosis. Maximum patients were in the age group 41-45 years out of which $10 \%$ of patients had adenomyosis with normal size uterus while $20 \%$ of patients had bulky uterus with adenomyosis as shown in Table 6.

\section{Discussion}

In 1972, Bird et al. defined adenomyosis as "Benign invasion of the endometrium into the myometrium, producing a diffusely enlarged uterus which microscopically exhibits ectopic, non-neoplastic, endometrial glands and stroma surrounded by heterotrophic and hyperplastic myometrium." ${ }^{\prime 9}$

In 1977 adenomyosis was very aptly described by Owolabi and Strickler as "the addendum to textbook chapters on ectopic endometrium; it is the forgotten process and a neglected diagnosis". ${ }^{10}$

Cullen classified adenomyoma into three different typesadenomyomata, subperitoneal or intraligamentary adenomyomata, and submucous adenomyomata. ${ }^{11}$

Adenomyosis is a condition in which there is uterine enlargement caused by ectopic rests of the endometrium. ${ }^{1}$

In our study, the main aim was to evaluate the efficacy of imaging diagnostic tools following clinical suspicion of adenomyosis.

Adenomyosis mainly affects women in the late reproductive age. A study done in 2019 showed that the largest group was of perimenopausal age (41-50 years) contributing $46 \%$ of total cases. ${ }^{12}$

The subjects with complaints of abnormal uterine bleeding with or without dysmenorrhea were recruited. Classically, the triad of uterine enlargement, dysmenorrhea, and menorrhagia suggests adenomyosis. ${ }^{13}$ A study done by Mechsner et al. found a positive correlation of adenomyosis with dysmenorrhea. ${ }^{14}$ Levgur et al. reported dysmenorrhea in $77.8 \%$ of patients with adenomyosis. ${ }^{5}$ In our study, all 31 subjects presented with dysmenorrhea. Dysmenorrhea was scaled based on the VAS scale and $35.48 \%$ of patients had a VAS score of less than 7 and $64.52 \%$ of patients had a score of more than 7. A total of $90.32 \%$ of the subjects presented with the chief complaint of heavy menstrual bleeding. A total of $9.68 \%$ of subjects presented with pain abdomen. A total of $64.52 \%$ of subjects had bleeding which lasted for less than 7 days and $35.48 \%$ of subjects had bleeding which lasted for more than 7 days. A total of $90 \%$ of the subjects presented with heavy menstrual bleeding along with dysmenorrhea. All the patients had congestive dysmenorrhea. 
A detailed record of menstrual rhythm was noted. The record of the previous three cycles was maintained.

Detailed history including personal and family history was taken. Per-vaginal (PV) examination was done in each patient appropriate for age, marital status, and to know pelvic anatomy and pathology in view of PALM-COEIN classification for the inclusion of adenomyosis. Matalliotakis et al. found out that the adenomyotic uterus was globular but rarely exceeded 12 weeks gestation in size. ${ }^{15}$ In our study, on bimanual examination, $64.52 \%$ of subjects had uterus of about $12-14$ weeks size and $35.48 \%$ had a normal-sized uterus.

A study done by Cirpan et al. showed anemia (HB level $<12 \mathrm{~g} / \mathrm{dL}$ ) due to menometrorrhagia was observed in $26.3 \%$ of patients. ${ }^{16}$

Radiological investigations including TVS and TAS were done.

In MRI, low signals junctional zone (JZ) $<8 \mathrm{~mm}$ excludes diagnosis whereas $\mathrm{JZ}>12 \mathrm{~mm}$ is suggestive of adenomyosis. MRI features include well-circumscribed, localized form adenomyoma, adenomyomatous polyp.

In our study, MRI was requisitioned for confirmation of diagnosis. Patients were counseled about the importance of MRI. A total of $32 \%$ of patients opted for an MRI in our study, which confirmed the findings of the ultrasound.

\section{Summary and Conclusion}

- The clinical diagnosis of adenomyosis has been called enigmatic largely because there are no pathognomonic symptoms of this disease.

- In our study, it was found out that adenomyosis mainly presents with menstrual irregularities along with dysmenorrhea.

- Clinical suspicion of adenomyosis was confirmed with radiological investigations including ultrasound. MRI was requisitioned. It was found out that out of the patients who had VAS score less than 7, 22.58\% had adenomyosis with normal uterus while $12.90 \%$ had bulky uterus with adenomyosis on ultrasound. Of the patients who had VAS score more than or equal to $7,9.68 \%$ had adenomyosis with normal uterus while $54.84 \%$ had bulky uterus with adenomyosis.

- MRI supplemented the ultrasound findings and was found useful in the confirmation of adenomyosis.

\section{References}

1. Cunningham F, Levono K, Bloom S, et al. Williams gynecology, 2nd edition. New York; McGraw-Hill Education; 2012. p. 259.
2. Naftalin J, Hoo W, Pateman K, et al. How common is adenomyosis? A prospective study of prevalence using transvaginal ultrasound in a gynaecology clinic. Hum Reprod 2012;27(12):3432-3439. DOI: 10.1093/ humrep/des332.

3. Exacoustos C, Brianza L, Di Giovanni A, et al. Adenomyosis: threedimensional sonographic findings of the junctional zone and correlation with histology, ultrasound in obstetrics and gynecology. Ultrasound Obstet Gynecol 2011;37(4):471-479. DOI: 10.1002/ uog.8900.

4. Munro MG, Critchley HOD, Broder MS, et al. FIGO classification system (PALM-COEIN) for causes of abnormal uterine bleeding in nongravid women of reproductive age. Int J Gynecol Obstet 2011;113(1):3-13. DOI: 10.1016/j.ijgo.2010.11.011.

5. Levgur M, Abadi MA, Tucker A. Adenomyosis: symptoms, histology, and pregnancy terminations. Obstet Gynecol 2000;95(5):688-691. DOI: 10.1016/s0029-7844(99)00659-6.

6. García-Solares J, Donnez J, Donnez O, et al. Pathogenesis of uterine adenomyosis: invagination or metaplasia? Fertil Steril 2018;109(3):371-379. DOI: 10.1016/j.fertnstert.2017.12.030.

7. Exacoustos C, Morosetti G, Conway F, et al. New sonographic classification of adenomyosis: do type and degree of adenomyosis correlate to severity of symptoms? J Minim Invasive Gynecol 2020;27(6):1308-1315. DOI: 10.1016/j.jmig.2019.09.788.

8. Champaneria R, Abedin P, Daniels J, et al. Ultrasound scan and magnetic resonance imaging for the diagnosis of adenomyosis: systematic review comparing test accuracy. Acta Obstet Gynecol Scand 2010;89(11):1374-1384. DOI: 10.3109/00016349.2010.512061.

9. Bird CC, McElin TW, Manalo-Estrelia P. The elusive adenomyosis of the uterus-revisited. Am J Obstet Gynecol 1972;112:583-593. DOI: 10.1016/0002-9378(72)90781-8.

10. Owolabi TO, Strickler RC. Adenomyosis: a neglected diagnosis. Obstet Gynecol 1977;50(4):424-427.

11. Cullen TS. Adenoma-myoma uteri diffusum benignum. Johns Hopkins Hosp Bull 1896;6:133.

12. Kumar CRA. Clinicopathological and radiological comparison of adenomyosis in hysterectomy patients-a retrospective study. Global J Res Anal 2019;8(10). DOI: 10.36106/gjra/0600459.

13. Hunter W, Smith L, Reiner W. Uterine adenomyosis, incidence, symptoms, and pathology in 1,856 hysterectomies. Am J Obstet Gynecol 1947;53(4):663-668.

14. Mechsner S, Grum B, Gericke C, et al. Possible roles of oxytocin receptor and vasopressin-1 a receptor in the pathomechanism of dysperistalsis and dysmenorrhea in patients with adenomyosis uteri. Fertil Steril 2010;94(7):2541-2546. DOI: 10.1016/j.fertnstert.2010.03.015.

15. Matalliotakis IM, Kourtis AI, Panidis DK. Adenomyosis. Obstet Gynecol Clin North Am 2003;30(1):63-82. DOI: 10.1016/s0889-8545(02)00053-0.

16. Cirpan TE, Yeniel O, Ulukus $M$, et al. Clinical symptoms and histopathological findings in subjects with adenomyosis uteri. Clin Exp Obstet Gynecol 2008;35(1):48-53. 